\title{
Creatinine Height Index in a Sample of Japanese Adults under Sedentary Activities
}

\author{
Tsuguyoshi SuzuKI, Tsukasa INAOKA, and Toshio KAWABE ${ }^{1}$ \\ Department of Human Ecology, School of Health Sciences, \\ Faculty of Medicine, University of Tokyo, \\ 7-3-1 Hongo, Bunkyo-ku, Tokyo 113, Japan
}

(Received March 12, 1984)

\begin{abstract}
Summary The value of creatinine height index (CHI), defined as milligrams of 24-h urinary excretion of creatinine divided by height in centimeters, was investigated on 21 healthy Japanese adults engaged in sedentary work. The average values were 10.58 in males and 6.68 in females. High partial correlation coefficients controlling sex were found among CHI, weight, fat-free mass, arm muscle area (AMA) and 24-h urinary excretion of creatinine. These indices had high loadings in the first factor of body size by principal component analysis. Regression of CHI on AMA differed in the intercept (i.e. the level of $\mathrm{CHI}$ at corresponding AMA) but not in the slope, from that studied under low-creatine diet in the U.S.A. Correcting AMA using arm bone area for Japanese and CHI with dietary factor, the relation between CHI and AMA in this study seemed to be in good agreement with that found in the U.S.A.

Key Words creatinine height index (CHI), active tissue mass, arm muscle area (AMA)
\end{abstract}

The 24-h urinary excretion of creatinine is widely accepted as an index of active tissue mass and is used for assessment of an individual's nutritional status (1). The creatinine height index $(\mathrm{CHI})$, defined as milligrams of urinary creatinine excreted in a 24-h period divided by the individual's height in centimeters, was originally standardized in America in a population of 30 healthy young adults (2), and has been recommended as an index of body muscle status since creatinine is an endproduct of muscle metabolism.

However, the CHI was suspected by Driver and McAlevy (3) to decline with age, although the $\mathrm{CHI}$ values they found were derived by dividing 24-h urinary excretion of creatinine by the constant height of $175 \mathrm{~cm}$ (values thus obtained showed a $20 \%$ decline from age 65 to 74 ). The low CHI measured in the elderly was suspected to have resulted from the decline of active tissue mass. However, no

1 鈴木継美, 稲岡 司, 河辺俊雄 
quantitative relations between $\mathrm{CHI}$ and active tissue mass-related indices were available.

This paper aims at determining the value of CHI in healthy Japanese adults living under sedentary conditions, and secondarily, elucidating the interrelationships of the $\mathrm{CHI}$ with other nutritional parameters, particularly with the arm muscle area. As far as we know, no reports which have dealt with $\mathrm{CHI}$ and its relationship to nutritional parameters have been published in Japan.

\section{SUBJECTS AND METHODS}

Subjects were healthy students, staff and officers of both sexes belonging to our Department. They numbered 14 males and 7 females.

Anthropometry was conducted by trained observers. Measurements included height, weight, midarm circumference (MAC) and skinfold thickness at triceps and subscapular sites (TSF and SSF, respectively). Height was measured using the Martin height-meter. Weight was measured for subjects with underwear only to the nearest $0.1 \mathrm{~kg}$. A black indelible ink mark was placed midway between the tip of the acromion and the olecranon process of the right arm. MAC measurement was taken to the nearest $\mathrm{mm}$ by wrapping the marked site with a vinyl tape, and TSF was also taken by vertically folding the marked site. SSF was measured on the right side of the body by folding the skinfold under the angle of the scapula. Duplicate skinfold readings were recorded using the Holtain skinfold caliper, and the second value was used for the analysis.

For each subject, a 24-h urine specimen was collected with the subject eating his usual diet to determine 24-h urinary excretion of creatinine. Creatinine was measured in an autoanalyzer in which the Jaffe reaction takes place (4).

Fat-free mass (FFM) was estimated using the following formulae $(5,6)$.

$$
\text { FFM }(\mathrm{kg})=\text { weight } \times(5.142-4.57 / \text { body density }),
$$

where

body density $\left(\mathrm{g} / \mathrm{cm}^{3}\right)=1.0913-0.00116 \times(\mathrm{TSF}+\mathrm{SSF}$ in $\mathrm{mm})$

$$
=1.0897-0.00113 \times(\mathrm{TSF}+\mathrm{SSF} \text { in } \mathrm{mm})
$$

(for females)

Arm muscle area (AMA), which was originally defined by Jelliffe (7), was calculated in two ways; (1) by the revised equation of Heymsfield et al. (8), and (2) by the new equation which we evolved to correct for the difference in arm bone area of Japanese adult males and females (9) from that of Americans.

Equation of Heymsfield et al:: 


$$
\text { AMA } \begin{array}{rlr}
\left(\mathrm{cm}^{2}\right) & =(\mathrm{MAC}-\pi \times \mathrm{TSF})^{2} / 4 \pi-10 & \text { (for males) } \\
& =(\mathrm{MAC}-\pi \times \mathrm{TSF})^{2} / 4 \pi-6.5 & \text { (for females) }
\end{array}
$$

Our equation:

$$
\text { AMA } \begin{array}{rlr}
\left(\mathrm{cm}^{2}\right) & =(\mathrm{MAC}-\pi \times \mathrm{TSF})^{2} / 4 \pi-9 & \text { (for males) } \\
& =(\mathrm{MAC}-\pi \times \mathrm{TSF})^{2} / 4 \pi-6.5 & \text { (for females) }
\end{array}
$$

The CHI, the ratio of $24-\mathrm{h}$ urinary excretion of creatinine to height, was also calculated.

\section{RESULTS}

Table 1 shows the physical characteristics of the subjects. Eight males were in their $20 \mathrm{~s}, 5$ males in $30 \mathrm{~s}$ and one male in his $50 \mathrm{~s}$. Seven females were in their $20 \mathrm{~s}$ to $50 \mathrm{~s}$. The means of $\mathrm{CHI}$ for males and females were respectively 10.38 and 6.68 .

Since sex difference was observed in all the variables but age, partial correlation analysis was conducted controlling sex (Table 2). The CHI correlated significantly with weight, $\mathrm{W} / \mathrm{H}^{2}$, FFM, both AMAs and 24-h urinary excretion of creatinine. The partial correlation coefficient of $\mathrm{CHI}$ with age controlling sex was not significant at the $5 \%$ level.

Table 3 compiles the results of principal component analysis using the variables of sex, age, height, weight, $\mathrm{W} / \mathrm{H}^{2}$, FFM, percentage fat, AMA, 24-h creatinine, and CHI. Three factors with eigenvalue over 1.0 were found. The loading of the first factor was high in sex, height, weight, FFM, AMA, 24-h urinary excretion of

Table 1. Physical characteristics of subjects.

\begin{tabular}{lcc}
\hline & $\begin{array}{c}\text { Male } \\
(n=14) \\
(\text { mean } \pm \mathrm{SD})\end{array}$ & $\begin{array}{c}\text { Female } \\
(n=7) \\
(\text { mean } \pm \mathrm{SD})\end{array}$ \\
\hline Age (year) & $31 \pm 8$ & $38 \pm 12$ \\
Height $(\mathrm{cm})$ & $166.8 \pm 5.8$ & $153.7 \pm 2.0$ \\
Weight $(\mathrm{kg})$ & $64.0 \pm 5.8$ & $48.7 \pm 7.4$ \\
$\mathrm{~W} / \mathrm{H}^{2}\left(\mathrm{~kg} / \mathrm{cm}^{2} \times 10^{4}\right)$ & $23.0 \pm 1.9$ & $20.6 \pm 2.8$ \\
Fat $(\%)$ & $17.0 \pm 5.4$ & $24.1 \pm 5.5$ \\
Fat-free mass $(\mathrm{kg})$ & $53.0 \pm 4.9$ & $36.7 \pm 3.4$ \\
Arm muscle area ${ }^{\mathrm{a}}\left(\mathrm{cm}^{2}\right)$ & $41.3 \pm 6.6$ & $27.8 \pm 5.4$ \\
Arm muscle area $\left(\mathrm{cm}^{2}\right)$ & $42.3 \pm 6.6$ & $27.8 \pm 5.4$ \\
$24-\mathrm{h} \mathrm{creatinine}\left(\mathrm{g} / \mathrm{day}^{2}\right)$ & $1.73 \pm 0.20$ & $1.03 \pm 0.20$ \\
$\mathrm{CHI}(\mathrm{mg} / \mathrm{cm})$ & $10.38 \pm 1.16$ & $6.68 \pm 1.27$ \\
\hline
\end{tabular}

${ }^{a}$ Calculated by the revised equation of Heymsfield et al. (8). ${ }^{\mathrm{b}}$ Calculated by our equation. ${ }^{\mathrm{c}}$ Ratio of 24 -h urinary excretion of creatinine to height. 
Table 2. Partial correlation matrix controlling sex between nutritional parameters.

\begin{tabular}{|c|c|c|c|c|c|c|c|c|c|}
\hline & Age & Height & Weight & $\mathrm{W} / \mathrm{H}^{2}$ & Fat $(\%)$ & $\mathrm{FFM}^{\mathrm{a}}$ & $\mathrm{AMA}^{\mathrm{b}}$ & $\mathrm{AMA}^{\mathrm{c}}$ & 24-h $\mathrm{Cr}^{\mathrm{d}}$ \\
\hline \multicolumn{10}{|l|}{ Height } \\
\hline Weight & & $.426^{*}$ & & & & & & & \\
\hline $\mathrm{W} / \mathrm{H}^{2}$ & & & $.833 * * *$ & & & & & & \\
\hline Fat $(\%)$ & & & $.569 * *$ & $.681^{* * *}$ & & & & & \\
\hline $\mathrm{FFM}^{\mathrm{a}}$ & & $.582^{* *}$ & $.736^{* * *}$ & $.454 *$ & & & & & \\
\hline $\mathrm{AMA}^{\mathrm{b}}$ & & & $.571^{* *}$ & $.627 * *$ & & $.584 * *$ & & & \\
\hline $\mathrm{AMA}^{\mathrm{c}}$ & & & $.571^{* *}$ & $.627 * *$ & & $.584^{* *}$ & & & \\
\hline 24-h Cr $\mathrm{Cr}^{\mathrm{d}}$ & & & $.667 * * *$ & $.557 * *$ & & $.757 * * *$ & $.424^{*}$ & $.424 *$ & \\
\hline $\mathrm{CHI}^{\mathrm{e}}$ & & & $.598 * *$ & $.637 * * *$ & & $.635 * * *$ & $.450^{*}$ & $.424 *$ & $.966 * * *$ \\
\hline
\end{tabular}

${ }^{\mathrm{a}}$ Fat-free mass. ${ }^{\mathrm{b}}$ Arm muscle area calculated by the revised equation of Heymsfield $e t$ al. (8). ${ }^{\mathrm{c}}$ Arm muscle area calculated by our equation. ${ }^{\mathrm{d}} 24-\mathrm{h}$ urinary excretion of creatinine. ${ }^{\mathrm{e}}$ Ratio of 24 -h urinary excretion of creatinine to height. ${ }^{*} p<0.05$, ${ }^{* *} p<0.01,{ }^{* * *} p<0.001$.

Table 3. Factor matrix using principal factors.

\begin{tabular}{lccc}
\hline Factor & Eigenvalue & $\begin{array}{c}\text { Percent of } \\
\text { variable }\end{array}$ & $\begin{array}{c}\text { Cummulative } \\
\text { percent }\end{array}$ \\
\hline 1 & 7.54 & 68.5 & 68.5 \\
2 & 1.48 & 13.5 & 82.0 \\
3 & 1.07 & 9.7 & 91.7 \\
\hline Variable & Factor 1 & Factor 2 & Factor 3 \\
\hline Sex & .904 & -.231 & -.025 \\
Age & -.340 & .054 & .893 \\
Height & .815 & -.315 & -.224 \\
Weight & .930 & .280 & -.091 \\
W/H & .696 & .695 & .043 \\
Fat $^{2} \%$ & -.421 & .845 & -.231 \\
FFM $^{\mathrm{a}}$ & .977 & -.126 & .031 \\
AMA $^{\mathrm{b}}$ & .894 & .143 & .291 \\
$24-\mathrm{h} \mathrm{Cr}^{\mathrm{c}}$ & .964 & -.038 & -.052 \\
CHI $^{\mathrm{d}}$ & .942 & .034 & -.017 \\
\hline
\end{tabular}

${ }^{\mathrm{a}}$ Fat-free mass. ${ }^{\mathrm{b}}$ Arm muscle area calculated by our equation. ${ }^{\mathrm{c}} 24$-h urinary excretion of creatinine. ${ }^{d}$ Ratio of 24 -h urinary excretion of creatinine to height.

creatinine and $\mathrm{CHI}$; thus it was assumed to be the body size factor. The second seemed to be the obesity factor because of high loadings in percentage fat and $\mathrm{W} / \mathrm{H}^{2}$, and the third was the ageing factor.

Figure 1 shows the scattergram of $\mathrm{CHI}$ with AMA using our equation. The CHI correlated slightly higher with AMA by our equation $(r=0.792, p<0.001)$ 


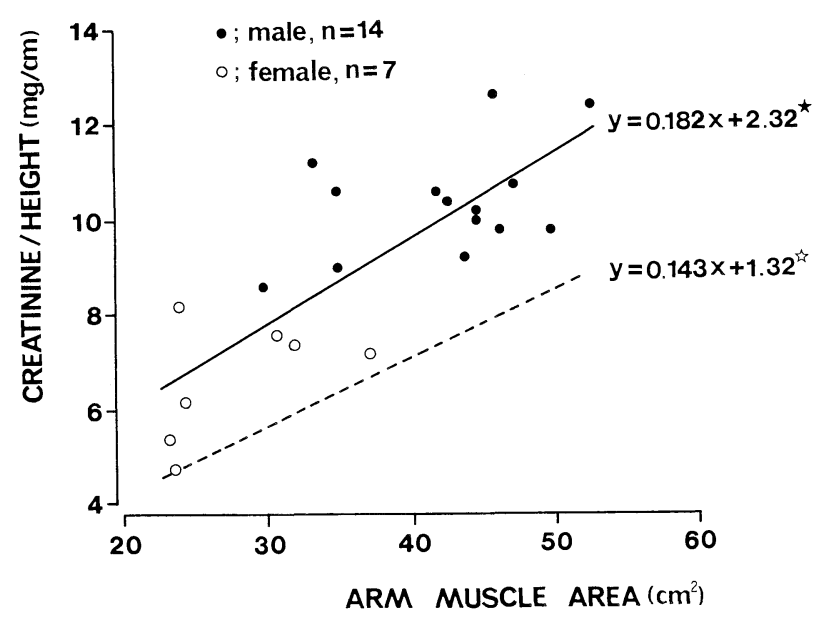

Fig. 1. Relation between CHI and arm muscle area (AMA). Regression equations indicate the result of present study, in which AMA was calculated by our equation $(\star, r=0.79)$, and that by Heymsfield et al. ( $\lesssim, r=0.95$, Ref. 8 ).

than with AMA by the equation of Heymsfield et al. $(r=0.775, p<0.001)$. For both AMAs, the slopes of the regression equation did not significantly differ from that reported by Heymsfield et al. (8), but the intercepts differed significantly (each $p<0.05$, ANACOVA). The upper shift of CHI for the same AMA was observed.

\section{DISCUSSION}

As the first step to standardize CHI for Japanese we selected healthy Japanese adults under sedentary living conditions, since the activity level of Japanese has been expected to decline as with other populations in developed countries, and thus they may be representative of such low activity populations. The present study gave values of $\mathrm{CHI}$ for the subjects with wide age-range and eating an ordinary diet, although the number of subjects was not sufficient to calculate average values of CHI for each 10-year age group. Comparing with the data of Saito et al. (personal communication), the values for our subjects, 10.38 in males and 6.68 in females, were within the ranges of those for their subjects of young age groups. The mean of $\mathrm{CHI}$ in our male subjects is also compatible to that for American young males (3), although their values were obtained by dividing $24-\mathrm{h}$ urinary excretion of creatinine by the constant height of $175 \mathrm{~cm}$.

In order to standardize CHI as a nutritional index, the age-related decline of CHI must be solved. In our study, CHI did not significantly correlate with age. This may be due to small sample size and to the distribution of subjects' ages. However, the partial correlation analysis controlling sex revealed that $\mathrm{CHI}$ correlated highly with weight, $\mathrm{W} / \mathrm{H}^{2}$, FFM, AMA and 24-h urinary excretion of creatinine. Some of 
them (FFM, AMA and 24-h urinary excretion of creatinine) have been already recognized to decline with age $(1,10,11)$. The fact that $\mathrm{CHI}$ correlated highly with 24-h urinary excretion of creatinine $(r=0.966, p<0.001)$ may reduce the value of $\mathrm{CHI}$ as a nutritional index. However, CHI correlated slightly higher with AMA than 24-h urinary excretion of creatinine did (Table 2). Further study is needed on a population with wide range of heights.

The intercept of the present regression of CHI on each of two AMAs was different from that reported by Heymsfield et al. (8). The formulae to calculate AMA have negative constants to correct overestimated fat area and arm bone area (ABA). Thus the difference of ABA among different ethnic groups was suspected to cause the observed difference in the relation of CHI to AMA. The ABA in the subjects of the study of Heymsfield et al. (8) was $4.2 \mathrm{~cm}^{2}$ in males and $2.5 \mathrm{~cm}^{2}$ in females. The ABA values of Japanese males and females were calculated at respectively $3.1 \mathrm{~cm}^{2}$ and $2.4 \mathrm{~cm}^{2}$, using the standard values of maximum and minimum diameters of the Japanese humerus (9) and assuming ABA as an ellipse. Therefore, we developed a new equation of AMA in this study for the Japanese. The regression of $\mathrm{CHI}$ with AMA using our equation showed a slightly higher correlation coefficient than that using the equation of Heymsfield et al. (8). The slope of the former regression was lower than the latter and was not significantly different from that reported by Heymsfield et al. (8). However, the intercept of each regression significantly deffered from that reported by them (8). The difference of 24-h urinary excretion of creatinine between their subjects and ours should be attributable to the difference of the intercepts of the regressions. Dietary factor is known to be one of the greatest factors affecting the 24-h urinary excretion of creatinine $(1,12-14)$. One hundred grams of meat intake increased urinary excretion of creatinine by around $150 \mathrm{mg} /$ day (12). Our subjects were tested under their ordinary diet, whereas those of Heymsfield et al. were tested under low creatine diet. If our subjects had reduced meat consumption by $100 \mathrm{~g}$ per day to lower their urinary excretion of creatinine by $150 \mathrm{mg} / \mathrm{day}$, the level of their $\mathrm{CHI}$ would have decreased by around 1.0. Then the mean values of $\mathrm{CHI}$ for both studies would have agreed.

Most of their subjects of Heymsfield et al. were patients with a low level of physical activity, which may have contributed to lower $\mathrm{CHI}$ than our subjects. But the effect seemed small since even temporary strenuous muscle activity has been shown to increase urinary excretion of creatinine by $5-10 \%$ above the ordinary level $(1,15,16)$. Thus, this study shows that a comparative study for CHI should be conducted in considering differences in subjects' dietary conditions.

\section{REFERENCES}

1) Heymsfield, S. B., Arteaga, C., McManus, C., Smith, J., and Moffitt, S. (1983): Measurement of muscle mass in humans: validity of the 24-hour urinary creatinine method. Am. J. Clin. Nutr., 37, 478-494.

2) Bistrian, B. R., Blackburn, G. L., Sherman, M., and Scrimshaw, N. S. S. (1975): 
Therapeutic index of nutritional depletion in hospitalized patients. Surg. Gynecol. Obstet., 141, 512-516.

3) Driver, A. G., and McAlevy, M. T. (1980): Creatinine height index as a function of age. Am. J. Clin. Nutr., 33, 2057.

4) Bonsnes, R. W., and Taussky, H. H. (1945): On the colorimetric determination of creatinine by the Jaffe reaction. J. Biol. Chem., 158, 581-591.

5) Brožek, J., Grande, F., Anderson, J. T., and Keys, A. (1963): Densitometric analysis of body composition: revision of some quantitative assumptions. Ann. N. Y. Acad. Sci., 110, 131-140.

6) Nagamine, S., and Suzuki, S. (1964): Anthropometry and body composition of Japanese young men and women. Hum. Biol., 36, 8-15.

7) Jelliffe, D. B. (1966): The assessment of the nutritional status of the community. WHO Monograph Series No. 63, WHO, Geneva, pp. 71-78.

8) Heymsfield, S. B., McManus, C., Smith, J., Stevens, V., and Nixon, D. W. (1982): Anthropometric measurement of muscle mass: revised equations for calculating bonefree arm muscle area. Am. J. Clin. Nutr., 36, 680-690.

9) Takahashi, Y. (1976): Anthropological studies on the humerus of the recent Japanese. Acta Anatomica Nipponica, 51, 79-88.

10) Tomlinson, B. E., Walton, J. N., and Rebeiz, J. J. (1969): The effects of ageing and of cachexia upon skeletal muscle-a histopathological study. J. Neurol. Sci., 9, 321-346.

11) Forbes, G. B., and Reina, J. C. (1970): Adult lean body mass decline with age: some longitudinal observations. Metabolism, 19, 653-663.

12) Kaneko, K., Amagai, S., and Koike, G. (1983): Effect of meat or protein intake on daily creatinine excretion in urine. J. Jpn. Soc. Nutr. Food Sci., (in Japanese with English summary), 36, 341-345.

13) Lykken, G. I., Jacob, R. A., Munoz, J. M., and Sandstead, H. H. (1980): A mathematical model of creatinine metabolism in normal males - comparison between theory and experiment. Am. J. Clin. Nutr., 33, 2674-2685.

14) Bleiler, R. E., and Schedl, H. P. (1972): Creatinine excretion: validity and relationships to diet and body size. J. Lab. Clin. Med., 59, 945-955.

15) Hobson, W. (1939): Urinary output of creatine and creatinine associated with physical exertion and its relationship to carbohydrate metabolism. Biochem. J., 33, 1425-1431.

16) Srivastara, S. S., Mani, K. V., Soni, C. M., and Bhati, J. (1957): Effect of muscular exercises on urinary excretion of creatine and creatinine. Ind. J. Med. Res., 55, 953-960. 